\title{
Mechanical behaviour of Ti-Nb-Hf alloys
}

\author{
R. Yang ${ }^{\mathrm{a}}$, K.M. Rahman ${ }^{\mathrm{a}}$, A.N. Rakhymberdiyev ${ }^{\mathrm{a}}$, D. Dye ${ }^{\mathrm{a}}$, \\ V.A. Vorontsov ${ }^{\text {a }}$ \\ ${ }^{a}$ Department of Materials, Royal School of Mines, Imperial College, Prince \\ Consort Road, South Kensington, London SW7 2BP, UK
}

\begin{abstract}
Ti-(24-26)Nb-(2-4)Hf at.\% alloys were designed by assuming that hafnium has a similar effect to zirconium in the Ti-Nb-Zr system. Alloy specimens were produced using vacuum arc melting and subsequently hot-rolled. Uniaxial tensile testing was then performed both at ambient temperature and in liquid nitrogen at $-196^{\circ} \mathrm{C}$. While the alloys showed no obvious superelastic behaviour, they exhibited pronounced strain hardening and could achieve high elongations before failure $(>30 \%$ engineering strain). Post-mortem examination revealed that the mechanism of strain hardening was extensive blue $\{332\}$ and/or $\{211\}$ deformation twinning. Twinning was found to be more prevalent in alloys with 2 at.\% Hf compared to those with 4 at.\%. The cryogenic temperature deformation also promoted deformation twinning when compared to ambient temperature results. As is the case with other metastable $\beta$-Ti alloys, maintaining control over the precipitation of $\omega$ phases was found to be crucial for attaining desirable mechanical behaviour. Further, microstructural engineering and alloying may be used to develop strong, lightweight alloys based on the Ti-Nb-Hf system with beneficial strain hardening characteristics for energy absorption, cryogenic and biomedical applications.
\end{abstract}

Key words: Titanium alloys, mechanical behaviour, deformation twinning, martensitic transformation, cryogenic testing

\section{Introduction}

Stabilising the body-centred cubic (b.c.c.) $\beta$ phase in titanium through alloying can yield improved and often unique mechanical properties. This has been exemplified by the introduction of near- $\beta$ alloys with excellent forgeability such as Ti-10V-2Fe-3Al [1] and Ti-5Al-5Mo-5V-3Cr [2] (wt.\%) in the aerospace industry and by the development of metastable- $\beta$ superelastic and shape memory alloys such as Gum Metal Ti-36Nb-2Ta3Zr [3] and IMR alloy Ti-24Nb-4Zr-8Sn [4] (wt.\%). 
Alloys based on the Ti-Nb binary system exhibit interesting variability in mechanical behaviour, e.g. shape memory and superelasticity, due to a straininduced martensitic transformation $[5,6]$. During this transformation the b.c.c. $\beta$ phase is transformed into twinned martensite variants of the orthorhombic $\alpha^{\prime \prime}$ phase. The mathematical description of the transformation has been described in detail by Lieberman et al. [7], as well as by Mackenzie and Bowles $[8,9]$. The martensite formation may occur in addition to conventional plastic behaviour attributable to dislocation glide and/or deformation twinning.

The characteristics of the $\beta$ to $\alpha^{\prime \prime}$ martensitic transformation in $\mathrm{Ti}-\mathrm{Nb}$ can be controlled through alloying with additional elements, which include Al, Pt, $\mathrm{Ta}, \mathrm{Zr}$ and Sn [10-15]. Among these, alloying with tantalum and zirconium has shown the greatest window for tailoring of mechanical behaviour [12]. The Ti-Nb-Ta-Zr quaternary system has thus resulted in a number of alloys that are collectively abbreviated to TNTZ. The superelastic properties of titanium alloys are strongly dependent on their oxygen content $[16,17]$ as well as the amount of athermal and isothermal $\omega$ phases [18,19]. Excess proportion of $\omega$ causes the superelasticity to diminish. Precipitation of isothermal $\omega$ (i.e. during isothermal ageing) results in rejection of $\beta$-stabilising solutes and formation of disperse $\alpha$ laths [18-20].

The most intensively studied and discussed TNTZ alloy has been Gum Metal [3]. The alloy was designed by applying the theoretical averaging principles put forward by Morinaga et al. [21,22] which use the molecular orbital concept. While originally it was suggested that the alloy's "super" properties were attributed to a dislocation-free faulting mechanism, it was subsequently demonstrated that the alloy deformed via the $\beta$ to $\alpha^{\prime \prime}$ martensitic transformation [23]. It was also demonstrated that the transformation is accompanied by dislocation glide and deformation twinning [24], especially during cyclic loading.

Deformation twinning has been exploited to obtain ultra-ductile steels with superb strain hardening characteristics, e.g. TWIP steels. This makes them superb materials for dynamic energy absorption [25]. Example applications include ballistic protection and automotive collision safety. If the same phenomena can be exploited in titanium alloys, it would provide lower density alternatives to steels for dynamic applications where the extra material cost is warranted. Despite the substantial ductility to failure and extensive transformation twinning observed in Gum Metal, the alloy does not exhibit any beneficial work hardening. This is also the case in a number of other alloys based on the Ti-Nb system $[26,12]$.

The Ti-Nb-Hf system has received very limited scientific attention to date. The primary interest has been from biomaterials research as the system can produce low-modulus biocompatible alloys that are reported to form twinned 
martensite phases $[27,28]$. In this work we investigate the mechanical properties of Ti-(24-26)Nb-(2-4)Hf at.\% alloys with a focus on structural applications and consider the perspectives for developing alloys with dynamic strain hardening.

\section{Experimental methodology}

\subsection{Alloy design}

The alloy compositions in this study were selected by assuming that hafnium has a similar effect on the martensite start $\left(M_{s}\right)$ temperature as zirconium. Thus, the alloys were designed with the aim of achieving a $\beta \rightarrow \alpha^{\prime \prime}$ transformation that would result in superelasticity or shape memory in the alloys.

The compositions were determined with reference to existing studies. In Ti(25-28) Nb alloys the $M_{s}$ increased by $43^{\circ} \mathrm{C}$ for every 1 at.\% of niobium added, with the $M_{s}$ of Ti-25Nb approximately at room temperature. In Ti-22Nb-(28)Zr the $M_{s}$ decreased by $38^{\circ} \mathrm{C}$ for every 1 at.\% of zirconium content [13]. Since there were no existing reports discussing effects of hafnium on the $M_{s}$ at the time of this writing, its effect was assumed equivalent to that of zirconium. The effects of niobium and hafnium on the martensitic transformation temperatures were assumed to be independent. The hafnium content was constrained to 2-6 at.\% due to its high melting point. It was thus, estimated that the Ti-(24-26) Nb-(2-6)Hf at.\% alloys would have the $M_{s}$ temperature ranging from -140 to $20^{\circ} \mathrm{C}$.

Final alloy compositions were derived using molecular orbital theory parameters $[29,21,22]$. These three parameters are the electron per atom ratio $(e / a)$, bond order $(B o)$ and metallic average $d$-electron orbital energy level $(M d)$. The properties related to martensites can be predicted by e/a ratio [29]. In quenched material, it is predicted that an $e / a$ ratio greater than 4.20 will result in a pure $\beta$ phase. Ti- $(25.5-27) \mathrm{Nb}$ at.\% alloys $(e / a$ 4.255-4.270, Bo 2.869-2.873, $M d 2.440-2.441 \mathrm{eV}$ ) showed superelastic behaviour at room temperature [16]. Ti-22Nb-6Zr at.\% (e/a 4.220, Bo 2.876, $M d 2.471 \mathrm{eV}$ ) exhibited the best superelastic behaviour at room temperature among Ti-22Nb- $(2-8) \mathrm{Zr}$ at.\% alloys [16]. Finally, Saito et al. put forward three electronic "magic numbers" for Gum Metals which were most likely to exhibit "super-properties" (including superelastity): $e / a \sim 4.24, B o \sim 2.87$, and $M d \sim 2.45 \mathrm{eV}$. With reference to the aforementioned studies, the final compositions of the four alloys investigated in this study were determined (i.e. Ti-(24-26)Nb-(2-6)Hf at.\%). The alloy design parameters are summarised in Table 1. 


\subsection{Alloy preparation and mechanical testing}

The alloys were produced from commercial purity titanium sponge $(<1200$ ppm oxygen), $99.9 \%$ niobium pellets and $99.7 \%$ hafnium bar. The elements were arc-melted in a water-cooled crucible under a back-filled argon atmosphere and cast into a copper mould to produce $\approx 300 \mathrm{~g}$ ingots with a $23 \times 23 \mathrm{~mm}$ cross section. The ingots were then heated to $1150{ }^{\circ} \mathrm{C}$ and, after a 30 minute furnace soak time, were hot-rolled using square profile rolls to produce $14 \times 14 \mathrm{~mm}$ cross section bars.

The material from the rolled bars was sectioned manually for metallographic characterisation and electric-discharge machined (wire EDM) to produce miniature tensile test specimens. The dog bone geometry specimens had a $19 \mathrm{~mm}$ gauge length and a $1.5 \times 1.5 \mathrm{~mm}$ cross section. Tensile testing was performed using a Zwick-Roell $100 \mathrm{kN}$ lead screw load frame. The specimens were tested to failure at $10^{-3} \mathrm{~s}^{-1}$ using a contact extensometer to record strain. Lowtemperature tests were performed at $-196^{\circ} \mathrm{C}$ in liquid nitrogen.

To investigate alloy stability, some specimens were encapsulated in quartz tubes with back-filled argon and annealed for $1 \mathrm{~h}$ at $800^{\circ} \mathrm{C}$ and subsequently quenched in water. Half of the annealed specimens were tested immediately and half were $\omega$-aged at $300^{\circ} \mathrm{C}$ for $24 \mathrm{~h}$ before tensile testing.

To reduce the grain size and improve the strength, Ti-24Nb-2Hf was sequentially cold rolled to $75 \%$ thickness, flash-annealed at $900{ }^{\circ} \mathrm{C}$ for $2 \mathrm{~min}$ and water-quenched. Thus, the $14 \mathrm{~mm}$ bar was rolled into a $1.5 \mathrm{~mm}$ plate, machined into dog bone specimens and tested in tension. Based on the initial test results, the effect of the flash annealing temperature on grain size was investigated in Ti-24Nb-2Hf cold-rolled to a $70 \%$ thickness reduction. Pieces of the alloy were flash-annealed for $1 \mathrm{~min}$ at different temperatures and examined in the light microscope to measure the average grain size (equivalent diameter) using ImageJ software. Due to the limited quantity of original ingot material Vickers hardness tests were performed.

\subsection{Material characterisation}

Specimens were prepared for scanning electron microscopy (SEM), transmission electron microscopy (TEM), visible light microscopy (LM) and X-Ray diffraction (XRD). For SEM, XRD and LM specimens were prepared using standard metallographic technique using $\mathrm{SiC}$ papers and $\mathrm{pH}$-neutral colloidal silica suspension. LM specimens were chemically etched using 8 vol.\% $\mathrm{HF}$ and $15 \mathrm{vol} . \% \mathrm{HNO}_{3}$ in water. LM imaging was performed on deformed specimens using cross-polarising filters to increase the contrast. 
SEM and XRD specimens were characterised in the polished condition. XRD measurements were made for the as-manufactured alloys using a Bruker D2 Phaser diffractometer. High-resolution EBSD mapping was performed on the deformed specimens using a Zeiss Sigma 300 field emission gun (FEG) SEM with a Bruker $\mathrm{e}^{-}$Flash EBSD detector. A working distance of $15 \mathrm{~mm}$ was used for the pattern acquisition.

For TEM specimen preparation, sections were made from the rolled bars using a rotary precision saw and $3 \mathrm{~mm}$ discs were cut using a spark-erosion unit. The discs were electrolytically polished in a Struers TenuPol-5 twin-jet unit using 8 vol. $\% \mathrm{H}_{2} \mathrm{SO}_{4}$ in methanol at $-40^{\circ} \mathrm{C}$ and $18 \mathrm{~V}$. Imaging was carried out using a JEOL JEM-2100Plus 200kV TEM with a $\mathrm{LaB}_{6}$ thermionic electron source.

\section{Results}

\subsection{Mechanical properties}

Figure 1(a) shows the ambient temperature tensile deformation behaviour of the four Ti-Nb-Hf alloys and the material parameters measured from the tests are summarised in Table 2. The stress vs. strain curves show that all four alloys deform in a ductile manner and exhibit strain hardening. There is no embrittlement at the point of failure. All alloy specimens showed notable gauge necking (Figure 4), which accounts for the apparent rapid strain softening (manifested as a stress drop) before failure. For conciseness, "yield stress" and "yield strength" will refer to $0.2 \%$ offset yield.

The curves in Figure 1(a) allow the effects of alloying to be distinguished. The tensile behaviour of the least alloyed composition, Ti-24-2, stands out prominently among the four alloys. It exhibits the lowest yield strength, $302 \mathrm{MPa}$, and the greatest ductility of $31.5 \%$. With an ultimate tensile strength (UTS) of $476 \mathrm{MPa}$, the alloy exhibits the highest extent of strain hardening, $\approx 174 \mathrm{MPa}$, when compared to the other compositions. The addition of another 2 at.\% of hafnium in Ti-24-4 increases the yield stress to $376 \mathrm{MPa}$, and results in the highest UTS , $505 \mathrm{MPa}$. However, these increases occur at the expense of ductility, which is reduced to $21.7 \%$. This may be a consequence of an additional solute hardening effect provided by the extra hafnium. Alternatively, dislocation glide starts to compete to a greater extent with deformation twinning (see Figure 4(b)) in Ti-24-4.

Raising the niobium content to 26 at.\% increases the yield strength, but lowers the UTS. In Ti-26-2 these values are $395 \mathrm{MPa}$ and $488 \mathrm{MPa}$ respectively, while in Ti-26-4 they were measured to be $400 \mathrm{MPa}$ and $466 \mathrm{MPa}$ respectively. There 
is an overall trend, whereby increasing the total amount of alloying elements leads to a reduction in overall ductility: $19.8 \%$ in Ti-26-2 and $15.2 \%$ in Ti-26-4. Another notable observation is the serrated yielding of the two alloys, which suggests that the active deformation mechanisms in these alloys are different. It is not possible to distinguish any obvious $\beta \rightarrow \alpha^{\prime \prime}$ double yield behaviour from the curves. However, for alloys with 2 at.\% hafnium, the changing overall post-yield gradients (particularly in Ti-26-2) suggest that, to a limited extent, the martensitic transformation might be taking place.

Figure 1(b) and Table 3 compare the mechanical performance of the alloys tested in tension at ambient temperature after annealing at $800^{\circ} \mathrm{C}$ for $1 \mathrm{~h}$. The heat treatment, which is intended to dissolve any existing $\omega$ phases, has a pronounced effect on the tensile behaviour of all four of the alloys. The specimens still fail in a ductile manner, but the tensile properties are markedly different. In the text that follows, the property change multiples with respect to the "as hot-rolled" condition are given in square brackets.

The most pronounced behaviour change is in the Ti-24-2 alloy, which now exhibits double yield behaviour that is characteristic of the $\beta$ to $\alpha^{\prime \prime}$ martensitic transformation. The yield strength is approximately halved from 302 to $146 \mathrm{MPa}$ [0.48], with secondary yield occurring at $\approx 250 \mathrm{MPa}$. The UTS and strain to failure have also reduced to $409 \mathrm{MPa}$ [0.86] and $26.4 \%$ [0.84] respectively. However, given the substantial drop in yield stress, the total work hardening and average hardening rate undergo a notable increase to give $263 \mathrm{MPa}$ [1.51] and 1.18 GPa [1.76] respectively.

The alloy Ti-24-4 also suffers a drop in yield strength and UTS, with values of $239 \mathrm{MPa}$ [0.63] and $441 \mathrm{MPa}$ [0.87] respectively. However, this is offset by an increase in failure strain to $28.3 \%$ [1.30]. The total work hardening and average work hardening rate are also improved, $202 \mathrm{MPa}[1.57]$ and $0.87 \mathrm{MPa}$ $[1.42]$.

In comparison, the alloy Ti-26-4 experiences similar effects on its tensile properties after the $800{ }^{\circ} \mathrm{C}$ heat treatment. The yield strength and UTS are also lowered in this alloy after the annealing treatment, $368 \mathrm{MPa}[0.92]$ and $417 \mathrm{MPa}$ [0.89] respectively. Likewise, the ductility of the alloy is also increased giving an overall failure stain of $22.5 \%$ [1.48]. The principal difference is that the alloy exhibits reduced strain hardening. The total work hardening and average work hardening rates are also improved, $49 \mathrm{MPa}$ [0.74] and 0.31 GPa [0.53]. The alloy still retains the serrated yield characteristic observed in the "as hot-rolled" material, indicating that dislocation glide rather than deformation twinning is still the dominant deformation mode.

Interestingly, Ti-26-2 undergoes changes that are opposite to those observed in the other three alloys. After the $800^{\circ} \mathrm{C}$ treatment it exhibits slightly in- 
creased yield stress and UTS, which rise to $431 \mathrm{MPa}$ [1.09] and $497 \mathrm{MPa}$ [1.02] respectively. The ductility of the alloy is reduced by the heat treatment to $15.1 \%$ [0.76]. The alloy also exhibits minimal work hardening, $66 \mathrm{MPa}$ [0.71], since the values of the yield stress and the UTS are close.

Figure 1(c) compares the mechanical performance of the alloys tested in tension at ambient temperature after annealing at $800^{\circ} \mathrm{C}$ for $1 \mathrm{~h}$, which was followed by ageing at $300^{\circ} \mathrm{C}$ for $24 \mathrm{~h}$. The bracketed values in Table 3 give the measured mechanical properties. The ageing treatment, was performed to promote the formation of isothermal $\omega$ phase precipitates. A pronounced effect on the tensile behaviour of all four of the alloys is clearly evident. As a general observation, all of the alloys exhibit noticeably increased UTS values and no strain hardening. The alloy Ti-24-2 showed complete embrittlement, failing at $0.7 \%$ strain without any observed plasticity. The UTS achieved by the alloy was $660 \mathrm{MPa}$. Ti-24-4 showed very little plasticity with mixed-mode failure at $2.6 \%$ strain and $695 \mathrm{MPa}$ UTS. The Nb-rich alloys Ti-26-2 and Ti-26-4 showed no embrittlement failing in a ductile manner after an initial period of subtle strain softening. The failure strains attained were $15.8 \%$ and $8.3 \%$ respectively for the two alloys. Both alloys no longer exhibited serrated yield behaviour, reaching UTS values of $634 \mathrm{MPa}$ and $556 \mathrm{MPa}$ respectively, which coincided with the yield point of the alloy.

As can be seen from Figure 2 and Table 4, the tensile deformation behaviour at $-196{ }^{\circ} \mathrm{C}$ is markedly different from room temperature behaviour. At this cryogenic temperature, the alloys should form some $\alpha^{\prime \prime}$ martensite because all the alloys are below $M_{s}$. The alloys show a dramatic increase in strength. This applies both to the yield stress and the UTS. The ductility of all the alloys is also increased, albeit to a different extent for each composition.

The alloy Ti-24-2 has a yield stress of $607 \mathrm{MPa}$, reaching a UTS of $1065 \mathrm{MPa}$ and fails after reaching a tensile strain of $35.5 \%$. In comparison, Ti-24-4 outperforms all of the other alloys on all three material parameters: with a yield stress of $626 \mathrm{MPa}$, a UTS of $1128 \mathrm{MPa}$ and a strain to failure equal to $40.9 \%$.

The alloys with 26 at.\% niobium exhibit a similar trend with respect to ductility. A higher hafnium content favours a greater elongation to failure at cryogenic temperature, $33.4 \%$ in Ti-26-4 vs. $30.8 \%$ in Ti-26-2. It also promotes a more ductile mode of failure with a greater extent of necking. The alloys with 4 at.\% also exhibit a higher degree of work hardening. Despite the greater ductility, Ti-26-4, which has the highest yield strength at room temperature, is the lowest strength alloy at $-196{ }^{\circ} \mathrm{C}$ with a yield and UTS of $477 \mathrm{MPa}$ and $1004 \mathrm{MPa}$ respectively. For comparison, Ti-26-2 has a yield stress of $650 \mathrm{MPa}$, a UTS of $1103 \mathrm{MPa}$ and strain to failure of $30.8 \%$. 


\subsection{Microstructural characterisation}

XRD and EBSD have shown the "as hot-rolled" alloys to be in the fully$\beta$ condition, with no h.c.p. $\alpha$ phases. This can be seen from the diffraction spectra in Figure 3 which show only reflections corresponding to the b.c.c. $\beta$ phase. SEM EDX analysis has shown that the final alloy compositions matched the nominal values.

The light micrographs and EBSD maps in Figure 4 show the post-mortem microstructures of the four alloys, which provide insight into the deformation mechanisms. In Figure 4(a) we see that all of the grains in Ti-24-2 are populated entirely by numerous deformation twins. This is also the case in Ti-24-4, Figure 4(b), but the twins have a coarser morphology. In comparison, Ti-26-2 in Figure 4(c) has grains that are only partially populated by coarse twins and Ti-26-4 in 4(d) has even even fewer twins still. The micrographs in Figures 4(c) and 4(d) explain the different stress vs. strain behaviour exhibited by Ti-26-2 and Ti-26-4 in Figure 1(a). It is evident that deformation twinning is being superseded by dislocation glide as the main mechanism of plastic strain accumulation. The serrated yield of both alloys would thus be consistent with strong dislocation-solute interactions (e.g. solute atmospheres). In all of the alloys, examples can be seen of twinning across multiple grains which have low relative misorientation. Failure appears to have occurred intra-granularly, largely along prior twin boundaries, where plastic strain was highly localised.

TEM dark-field imaging, Figure 5, revealed that all of the alloys contained dispersions of $\omega$ phase precipitates in the "as hot-rolled" condition. All of the complementary diffraction patterns show distinct $\omega$ spots as well as some diffuse streaking. This indicates that both isothermal and athermal $\omega$ variants are present in the specimens. The alloys containing 4 at.\% hafnium have less well defined isothermal $\omega$ spots and more pronounced athermal streaking. These alloys also appear to have more uniform precipitate distributions, whereas in specimens with 2 at.\% of hafnium there are areas where the precipitates are more densely clustered. It is also worth noting that the precipitates in Ti-26-2 appear noticeably coarser than in the other three alloys. Taking into account the differences between the two crystallographic viewing directions, $\langle 110\rangle$ vs. $\langle 113\rangle$, this coarse $\omega$ morphology still stands out.

Figure 6 shows post-mortem EBSD maps of the four alloys subjected to annealing at $800^{\circ} \mathrm{C}$ for $1 \mathrm{~h}$. Alloys Ti-24-2 and Ti-24-4 both exhibit very pronounced twinning within the grain interiors, Figures 6(a) and (b). These observations are consistent with the strain hardening behaviour observed from the tensile test data in Figure 1(b). Furthermore, the morphology of the twins is different between the two alloys. Ti-24-2 has very fine closely-spaced paired straight twins. Their chevron-like morphology is typical of twinned $\alpha^{\prime \prime}$ martensite. Ti- 
24-4 has larger highly-distorted individual twins with a wavier, more-lenticular morphology that are more characteristic of $\beta$ deformation twins, although some chevron-like twins are present as well. This difference is in agreement with the tensile test data, providing a likely explanation for the double yield behaviour of Ti-24-2. It should be noted that all of the sucessfully indexed pixels correspond to the b.c.c. $\beta$ phase.

Figure 6(c) clearly shows minimal twinning in alloy Ti-26-2. The EBSD map reveals significant orientation variations arising due to the rotations induced by plastic strain within the grain interior. Very fine slip bands are visible in the central grain. The grain boundaries are populated with numerous sub-grains. It is clear that dislocation glide is the dominant mechanism of plastic strain accumulation, which explains the negligible strain hardening observed in this alloy, Figure 1(b). Ti-26-4, in Figure 6(d), shows a partly similar strained microstructure featuring strain field contrast, slip bands and a few fine subgrains at the grain boundaries. However, it also exhibits a sparse population of coarse deformation twins. The limited ability to sustain some deformation twinning alongside the prevalent dislocation glide is the likely source of the alloy's improved ductility over Ti-26-2.

The post mortem microstructures of the alloys after $\omega$ ageing at $300{ }^{\circ} \mathrm{C}$ for $24 \mathrm{~h}$ are shown in Figure 7 as EBSD maps. It is clear that no $\alpha$ phase was observed in any of the alloys. Ti-24-2, which underwent complete embrittlement, exhibits no plastic deformation within the grain interiors. This is in line with the brittle intergranular failure mode observed in the alloy. In Ti-24-4 there is very limited orientation variation within the grain interiors, which is consistent with the very limited ductility observed during the tensile test. It is clear that the ageing treatment has had much less impact on alloys containing 26 at.\% of niobium, which is in line with its stabilising effect on the b.c.c. $\beta$ phase. Plastic strain localisation is evident in the form of slip bands in both Ti-26-2 and Ti-26-4, Figures 7(c) and 7(d). Therefore, both the EBSD maps and tensile test data confirm that the alloys with a higher niobium content are better at sustaining dislocation glide and are more resistant to embrittlement by precipitation of the $\omega$ phase. It can also be concluded that the $\omega$ ageing treatment suppresses deformation twinning in all four of the alloys.

The stress vs. strain curves in Figure 2 clearly indicate that there are changes in the deformation mechanisms when the alloys are tested in liquid nitrogen. Insight into the origin of these changes can be gained from examining the light micrographs and EBSD maps in Figure 8. The main distinction is the substantial increase in the extent of deformation twinning within all of the alloys, particularly in Ti-24-4, Ti-26-2 and Ti-26-4, where noticeable increases in overall ductility were observed. In comparison with room temperature deformation, the grain interiors of these alloys are now fully twinned. All of the alloys show an apparent refinement in the size of the deformation twins 
at $-196{ }^{\circ} \mathrm{C}$. Furthermore, the twins have a straighter, more linear morphology compared to the wavy and more lenticular appearance observed after ambient temperature testing. Despite the increase in overall ductility, the mode of fracture in all four alloys is more brittle than ductile. Ti-26-4 has retained the most ductility during fracture, which is evident from the necking in Figure 8(d). In contrast, Ti-24-2 shows an almost entirely brittle mode of failure with negligible necking and intra-granular cleavage. It can be seen from Figures 2 and 8 that a more ductile mode of failure is favoured by greater solute content.

\subsection{Grain size effects}

Figure 9 presents a trial investigation into the effect of grain refinement processing on the properties of Ti-24-2. The particular alloy was selected to undergo the treatment because it exhibited the greatest overall strain hardening and overall ductility during room temperature deformation in the "as hotrolled" state. It has been demonstrated that a substantial increase in the yield strength and UTS can be obtained in TWIP steels with minimal loss in overall ductility through grain refinement processing [32]. Such processing involves cold rolling to large reductions (e.g. to $50 \%$ thickness) followed by short-duration "flash annealing" at elevated temperatures. The current understanding is that the reduction in the grain size increases the threshold stress for twin nucleation. This effect acts in conjunction with conventional Hall-Petch type grain size strengthening, whereby the grain boundaries act as obstacles that impede the transfer of plasticity carrier defects, (i.e. dislocations and deformation twins), between adjacent grains.

Figure 9(a) shows that grain refinement does indeed noticeably increase the yield strength and UTS of Ti-24-2 (370 and 614 MPa respectively). This amounts to respective increases of 23 and $29 \%$ resulting from the reduction of average grain size from $\sim 97$ to $\sim 11 \mu \mathrm{m}$. However, this comes at the cost of a reduced strain to failure, which is lowered from $31.6 \%$ to $11.7 \%$. The alloy still fails in a ductile fashion with considerable necking within the gauge area. The experiment thus shows that it is not possible to increase the strength through a grain size reduction without significantly lowering the strain to failure. The observation may have two possible causes.

First, the experiment assumed that grain size refinement would have a similar effect in b.c.c. $\beta$ titanium alloys as it does in f.c.c. austenitic TWIP steels. Given the differences in crystal structure, and hence the operative mechanisms for deformation twinning [33], this may not be the case.

In f.c.c. crystals, deformation twins typically form on one of four crystallographically non-equivalent close-packed $\{111\}$ planes each of which con- 
tains three close-packed $\langle 110\rangle$ directions. Conventional deformation twinning in b.c.c. crystals occurs on one of twelve non-close-packed $\{211\}$ planes each of which hosts only one close-packed $\langle 111\rangle$ direction. While there are 12 available systems for twinning in both crystals, the restriction of dislocation and twin activity that results from the grain size reduction may have fundamentally different effects on the ability of the alloys to sustain the desirable large levels of plastic strain before failure. Furthermore, metastable $\beta$ titanium alloys exhibit an alternative $\{332\}\langle 113\rangle$ deformation twinning mechanism [34]. Alloys based on the Ti-Nb binary system, including Ti-24Nb-X (at.\%), have also been found to exhibit this type deformation twinning scheme [31]. The exact mechanism of $\{332\}\langle 113\rangle$ has still not been fully described, but it has been shown to accompany the $\beta$ to $\alpha^{\prime \prime}$ martensitic transformation in Ti-23.3Nb-0.7Ta-2.0Zr (at.\%) [35].

Secondly, during grain refinement processing the alloy specimen (rolled into a $1.5 \mathrm{~mm}$ plate) was annealed twice at $900^{\circ} \mathrm{C}$ for $2 \mathrm{~min}$ followed by quenching in water. Given the comparatively high temperature and quenching method used for the process, it is possible that some oxygen had diffused into the alloy. Dissolved oxygen is known to alter the behaviour of titanium alloys, particularly in the metastable $\beta$ family, generally leading to a reduction in ductility [30], as well as suppression of deformation twinning [36,34] and superelasticity (i.e. reversible martensitic transformations) [17,31].

Figure 9(b) summarises the effect of 1 min "flash" annealing temperature on grain refinement in Ti-24-2 that had been cold-rolled to a $70 \%$ thickness reduction. It can be seen that, on the whole, the grain size can be controlled reliably through adjustments in annealing temperature. Decreasing the annealing temperature also reduces the average grain size in the alloy. This reduction coincides with an apparent though small increase in the Vickers hardness of the specimens, although there is significant variability in the data. The obtained values give a fitted Hall-Petch hardening coefficient $k_{y}=53.5$ and single crystal hardness of 151(VHN).

\section{Discussion}

The Ti-(24-26)Nb-(2-4)Hf (at.\%) alloys investigated in this study exhibit a broad range of mechanical behaviour that is highly dependent on two factors. Firstly, it depends on the prior alloy processing route and heat treatment, which control the alloy microstructure. The second factor is the temperature of the alloy, which controls the interplay between the different deformation mechanisms that are possible in $\beta$ titanium alloys.

The obtained light micrographs and EBSD data (Figure 4) show clearly that 
deformation twinning takes place in all four of the alloys, but the extent of twinning and its prevalence over dislocation glide depends on the composition of the alloy and its temperature. The amount of twinning observed in the alloys correlates directly with their ability to exhibit dynamic Hall-Petch strengthening effects. The extent of twinning also correlates with the observed ductility, i.e. the strain sustained before failure. An additional level in the complexity of deformation arrises from the "double yield" behaviour observed in some alloys, which suggests the formation of martensite.

To better understand the nature of twinning in the Ti-(24-26)Nb-(2-4)Hf (at.\%) alloys, it is important to identify the crystallographic type of the twins. Figure 10 presents the twin boundary analysis for the non $\omega$-aged specimen EBSD data, as implemented in the Bruker Esprit 2.0 software package. While it is clear that not all of the twin boundaries were indexed, it is still possible to obtain a qualitative understanding of the twinning phenomena. The indexed twin boundaries are colour coded: blue for $\{332\}$ and red for $\{211\}$ major twinning systems. The less common $\{411\},\{222\},\{310\}$ and $\{321\}$ twin planes are coloured yellow, magenta, orange and grey respectively. The boundary colours are superimposed over the band contrast image combined with the $\{110\}\langle\overline{1} 1 \overline{1}\rangle$ Schmid factor map with respect to the loading direction. Table 5 summarises the indexed proportions of the twin boundary types observed in the specimens.

In the "as hot-rolled" alloys a clear compositional dependence of the twining mechanism can be observed. Alloys with 4 at.\% hafnium appear to favour $\{211\}$ twinning, whereas $\{332\}$ twins are prevalent in alloys with 2 at.\% hafnium. Ti-24-4 and Ti-26-4 also exhibit an increased proportion of $\{411\}$ twin boundaries at approximately $9 \%$ in both alloys. It is difficult to identify the origin of these less common twin boundaries from the maps in Figure 10. It is possible that they help accommodate the high curvature of some twins by providing a coherent interface. Increasing the niobium content noticeably reduces deformation twinning and shifts the plasticity mechanism towards the prevalence of dislocation glide. This is evident both from the micrographs and from the stress-strain behaviour. This is expected because niobium is a $\beta$ stabilising element. Furthermore, its stabilising effect is also evident from the increased amount of $\{211\}$ twinning in alloys containing 26 at.\% niobium when compared to those with just 24 at.\% niobium. The proportions of the minor twin planes are generally negligible in the four alloys except the $4.3 \%$ of $\{321\}$ twin boundaries in Ti-26-4. Given the low amount of deformation twinning in this alloy, however, the implications of this observation are unlikely to be of significance to the overall deformation behaviour.

The $\beta$-annealed alloys appear to display different twinning characteristics to the "as hot-rolled" specimens. The most interesting behaviour is that of Ti24-2. While $\{332\}$ twin boundaries are still in the majority, their proportion 
is now $45.2 \%$ vs. the $94.2 \%$ in the "as hot-rolled" material. The $\{211\}$ twin boundaries now comprise a comparable $35.6 \%$ and this is accompanied by $8.9 \%$ $\{411\}$ twin boundaries. Unusually, $9.3 \%$ of the indexed twin boundaries are $\{310\}$, and this great a proportion is not observed in any of the other cases. Given the very characteristic "double yield" stress-strain behaviour of the alloy, it is reasonable to suggest that these twin boundaries may be associated with $\alpha^{\prime \prime}$ martensite formation. The chevron-like morphology of the finer twins also seems to support this.

In contrast, the Ti-24-4 the twinning characteristics are largely unaltered with approximately the same proportions of $\{332\}$ and $\{211\}$ twin boundaries observed as in the "as hot-rolled" specimen. Ti-26-2 exhibited a minimal amount of deformation twinning as is evident from the EBSD data (Figure 6) and the stress-strain curve (Figure 1), which showed negligible strain hardening. Thus, a statement that the prevalence of twinning reverses form $\{332\}$ to $\{211\}$ relative to the "as hot-rolled" state would have limited validity given the low sample size (i.e. area analysed). The prevalent twin boundary type in Ti-26-4 is $\{332\}$ at $74.9 \%$ according to the analysis. Similarly to Ti-26-2, deformation twinning is not the main mode of plastic strain accumulation. However, it is possible the dissolution of $\omega$ phases by the $\beta$-annealing heat treatment has resulted in a more metastable alloy capable of sustaining a limited amount of $\{332\}$ twinning that is still largely outcompeted by dislocation glide.

Annealing the alloys at $800^{\circ} \mathrm{C}$ for $1 \mathrm{~h}$ has an effect that is consistent with the dissolution of isothermal $\omega$ phases. Increasing the hafnium content improves the ductility of the annealed alloy. The ductility increase is evident when deformation twinning dominates plasticity (Ti-24-4) and also when dislocation glide is prevalent (Ti-26-4). A possible explanation for this is that hafnium acts as an oxygen scavenger element and reduces the proportion of oxygen in solid solution by binding with it. This would alleviate the detrimental effects of the dissolved oxygen on ductility [16,30,31]. Meanwhile, increasing the niobium fraction allows improved retention of strength after annealing. This may be a result of slower grain growth during the annealing treatment due to the lower diffusivity of niobium. The higher niobium content also stabilises the b.c.c. $\beta$ phase, and thus favours dislocation glide over deformation twinning as the prevalent mode of plastic deformation.

Deformation at at $-196^{\circ} \mathrm{C}$ is entirely dominated by twinning as is evident from the micrographs in Figure 8. The stress-strain data (Figure 2) show that lowering the temperature of the alloys promotes twinning during deformation and hence dynamic Hall-Petch strengthening. The temperature transition from slip to twinning as the dominant mechanism of plasticity can be very gradual, and both competing modes can operate simultaneously [37]. This is clearly evident in more stable alloys with higher solute content, e.g. Ti-26-2 and Ti-26-4. The transition typically arises as a result of the difference in strain- 
hardening rates and temperature sensitivities of the two deformation modes [38]. At $-196^{\circ} \mathrm{C}$, the critical resolved shear stress for dislocation glide must be considerably greater than the twinning stress. In addition, the increased dynamic Hall-Petch strain hardening due to the twinning would further inhibit dislocation glide.

The twin boundary indexing analysis shows that in all alloys except Ti-24-2, the deformation is primarily via the $\{332\}$ twinning mechanism. It should be borne in mind that, due to the exceptionally high number density and fine morphology of the twins, the overall boundary indexing rate is lower in Ti-244 than in the other specimens. As is the case with the "as hot-rolled" alloys at ambient temperature, the higher hafnium concentration in Ti-24-4 and Ti26-4 seems to correlate with an increased proportion of $\{411\}$ boundaries. The higher niobium content of Ti-26-2 and Ti-26-4 appears to have shifted the twinning mode almost entirely in favour of $\{332\}$, with over $89 \%$ of the indexed twin boundaries belonging to that system. In alloys Ti-24-2 and Ti$24-4$ the split between the $\{332\}$ and $\{211\}$ mechanisms is considerably more even, as can be seen from Table 5 .

The test temperature of $-196{ }^{\circ} \mathrm{C}(77 \mathrm{~K})$ is considerably lower than the estimated $M_{s}$ temperatures of the four alloys. Thus, it is highly probable that at least some proportion of the $\beta$ phase in the specimens transformed to $\alpha^{\prime \prime}$ martensite upon cooling. This martensite would then continue to deform by forming progressively finer generations of martensite twins, alongside the deforming $\beta$ phase. Upon completion of the test, the martensite twins in the failed specimens would transform to twinned $\beta$ as the alloys reached ambient temperature. Given the differences in the estimated transformation temperatures between the alloys, the fraction of the $\beta$ phase that transforms to $\alpha^{\prime \prime}$ would decrease with increasing solute content. This may be responsible for the differences in the proportions of $\{332\}$ and $\{211\}$ observed.

The strain hardening behaviour of Ti-24-2 and Ti-26-2 alloys is also worth noting. There is evidence of "double yield" behaviour at $\approx 900 \mathrm{MPa}$ and at $\approx 870 \mathrm{MPa}$ respectively, highlighted by arrows on Figure 2 . This suggests that the strain-induced $\beta$ to $\alpha^{\prime \prime}$ martensitic transformation is taking place alongside deformation twinning. However, the double yield behaviour of both alloys is considerably more subtle and is not as pronounced as that observed in the $\beta$-annealed Ti-24-2 tested at ambient temperature in Figure 1. In the case of Ti-24-2, the observed twin boundary fractions for the $\{332\}$ type are close in the "as hot-rolled" and liquid nitrogen immersed specimens (45.2 and $46.9 \%$ respectively). The apparent "double yield" in Ti-24-2 at $-196^{\circ} \mathrm{C}$ is too subtle to be conclusive. It is more pronounced in Ti-26-2, which has a greater fraction of $\{332\}$ twin boundaries.

The observations for Ti-24-2 and Ti-26-2 at $-196^{\circ} \mathrm{C}$ are in agreement with the 
$\{332\}$ twinning mechanism proposed by Lai et al. [35]. The authors propose that $\{332\}$ twins nucleate within $\alpha^{\prime \prime}$ martensite [35], based on observations in a Ti-36Nb-2Ta-3Zr wt.\% alloy. However, the apparent absence of a "double yield" in Ti-24-4 and Ti-26-4 which also exhibit $\{332\}$ twins goes against this theory. Furthermore, the fraction of $\{332\}$ twin boundaries generally increases as the estimated $M_{s}$ temperature decreases. This implies that the alloys which are expected to have have smaller $\alpha^{\prime \prime}$ martensite fractions upon cooling to $196^{\circ} \mathrm{C}$ form more $\{332\}$ twins, which is contrary to Lai et al. Generally, the data indicate that, in addition to the effect of any existing $\omega$ phase distributions, the stress-induced martensitic transformation in Ti-(24-26) Nb-(2-4)Hf (at.\%) alloys is also very dependent on the temperature, and appears to be promoted at cryogenic temperatures in "as hot-rolled" specimens.

In summary, the post-mortem characterisation of the alloys suggests that the active deformation mechanisms in the Ti-(24-26)Nb-(2-4)Hf (at.\%) alloys are very complex. There is apparent competition between $\{332\}$ and $\{211\}$ deformation twinning, as well as dislocation glide and, in some cases, the stressinduced $\alpha^{\prime \prime}$ martensitic transformation. The true nature of the interplay between these mechanisms can only be characterised using in-situ loading and temperature control experiments employing synchrotron X-ray scattering and EBSD. While these methods would provide a direction for fascinating further research, they are beyond the scope of this study.

\section{Conclusions}

This study has investigated the mechanical behaviour of Ti-(24-26)Nb-(2-4)Hf (at.\%) alloys at both ambient and cryogenic temperatures when tested in uniaxial tension. The following conclusions can be made based on the obtained experimental data:

(1) Dynamic Hall-Petch strain hardening effects can be successfully exploited in Ti-(24-26)Nb-(2-4)Hf (at.\%) alloys which exhibit deformation twinning.

(2) Twinning is more prominent in less stable alloys with a lower concentration of alloying elements, especially the $\beta$-stabilising niobium. Greater proportions of alloying additions $\mathrm{Nb}$ and $\mathrm{Hf}$ favour dislocation glide over twinning. Since both slip and twinning can occur simultaneously, alloying can be used to fine tune their contributions to overall plastic deformation and thus attain desirable mechanical behaviour.

(3) The mechanical behaviour of the alloys is very sensitive to the precipitation of $\omega$ phases. High-temperature annealing at $800^{\circ} \mathrm{C}$ to dissolve $\omega$ precipitates can improve the mechanical properties. In Ti-24Nb-2Hf this treatment activates the $\beta \rightarrow \alpha^{\prime \prime}$ martensitic transformation. Deliberate 
ageing in of isothermal $\omega$ at $300^{\circ} \mathrm{C}$ has a very detrimental effect on the mechanical behaviour, either embrittling the alloys or completely eliminating any strain hardening capability.

(4) Thermo-mechanical processing can be successfully used to control the grain size in Ti-24Nb-2Hf. This increases the yield strength and UTS, but at a noticeable reduction in failure strain.

(5) During deformation at cryogenic temperature, $-196^{\circ} \mathrm{C}$, dislocation glide is suppressed and twinning is promoted in all four of the alloys studied. This results in a dramatic improvement in mechanical properties, especially the strain hardening response when compared to room temperature deformation.

(6) The EBSD analysis has shown that both $\{332\}$ and $\{211\}$ deformation twinning occur in the studied alloys. Which of the two modes prevails depends strongly on the alloy composition, the deformation temperature and the existence of $\omega$ phases. This is consistent with deformation mechanisms observed in other metastable $\beta$ phase alloys based on the $\mathrm{Ti}-\mathrm{Nb}$ system.

The Ti-Nb-Hf alloys studied are particularly promising materials for biomedical applications. The good biocompatibility of the alloying elements in conjunction with low elastic moduli make them suitable for orthopaedic implants. At the same time, their comparatively low strengths, good ductility and strain hardening characteristics make them perspective materials for production of surgical stents. The alloys may also may also find potential uses for lowtemperature applications such as cryogenics and space exploration since their mechanical properties are substantially improved at $-196^{\circ} \mathrm{C}$.

\section{Acknowledgements}

VAV would like to acknowledge gratefully the funding support of from RollsRoyce plc and Imperial College London under the Junior Research Fellowship scheme. VAV and DD also acknowledge funding from the EPSRC, UK under grant EP/L025213/1.

\section{References}

[1] M. Jackson, N. G. Jones, D. Dye, R. J. Dashwood, Effect of initial microstructure on plastic flow behaviour during isothermal forging of Ti-10V2Fe-3Al, Mat. Sci. Eng. A 501 (12) (2009) 248-254.

[2] N. G. Jones, R. J. Dashwood, D. Dye, M. Jackson, Thermomechanical processing of Ti-5Al-5Mo-5V-3Cr, Mat. Sci. Eng. A 490 (12) (2008) 369-377. 
[3] T. Saito, T. Furuta, J.-H. Hwang, S. Kuramoto, K. Nishino, N. Suzuki, R. Chen, A. Yamada, K. Ito, Y. Seno, T. Nonaka, H. Ikehata, N. Nagasako, C. Iwamoto, Y. Ikuhara, T. Sakuma, Multifunctional alloys obtained via a dislocation-free plastic deformation mechanism, Science 300 (2003) 464-467.

[4] Y. L. Hao, S. J. Li, S. Y. Sun, C. Y. Zheng, Q. M. Hu, R. Yang, Super-elastic titanium alloy with unstable plastic deformation, Appl. Phys. Lett. 87 (9) (2005) 091906.

[5] H. Y. Kim, H. Satoru, J. I. Kim, H. Hosoda, S. Miyazaki, Mechanical properties and shape memory behavior of Ti-Nb alloys, Mater. T. JIM 45 (7) (2004) 24432448 .

[6] H. Y. Kim, Y. Ikehara, J. I. Kim, H. Hosoda, S. Miyazaki, Martensitic transformation, shape memory and superelasticity of Ti-Nb binary alloys, Acta Mater. 54 (2006) 2419-2429.

[7] D. S. Lieberman, M. S. Wechsler, T. A. Read, Cubic to orthorhombic diffusionless phase change - experimental and theoretical studies of AuCd, J. Appl. Phys. 26 (1955) 473-484.

[8] J. K. Mackenzie, J. S. Bowles, The crystallography of martensite transformations II, Acta Metall. 2 (1954) 138-147.

[9] J. K. Mackenzie, J. S. Bowles, The crystallography of martensite transformations - IV body-centred cubic to orthorhombic transformations, Acta Metall. 5 (1957) 137-149.

[10] T. Inamura, Y. Fukui, H. Hosoda, K. Wakashima, S. Miyazaki, Relationship between texture and macroscopic transformation strain in severely cold-rolled Ti-Nb-Al superelastic alloy, Mater. T. JIM 45 (4) (2004) 1083-1089.

[11] H. Y. Kim, H. Oshika, J. I. Kim, T. Inamira, H. Hosoda, S. Miyazaku, Martensitic transformation and superelasticity of Ti-Nb-Pt alloys, Mater. T. JIM 48 (3) (2007) 400-406.

[12] H. Y. Kim, J. Fu, H. Tobe, J. I. Kim, S. Miyazaki, Crystal structure, transformation strain, and superelastic property of Ti-Nb-Zr and Ti-Nb-Ta alloys, Shap. Mem. Superelasticity 1 (2015) 107-116.

[13] J. I. Kim, H. Y. Kim, T. Inamura, H. Hosoda, S. Miyazaki, Shape memory characteristics of $\mathrm{Ti}-22 \mathrm{Nb}-(2-8) \mathrm{Zr}($ at.\%) biomedical alloys, Mat. Sci. Eng. A 403 (2005) 334-339.

[14] E. Takahashi, T. Sakurai, S. Watanabe, N. Masahashi, S. hanada, Effect of heat treatment and sn content on superelasticity in biocompatible TiNbSn alloys, Mater. T. JIM 43 (12) (2002) 2978-2983.

[15] F. Nozoe, H. Matsumoto, T. K. Jung, S. Watanabe, T. Saburi, S. Hanada, Effect of low temperature ageing on superelastic behaviour in biocompatible $\beta$ TiNbSn alloys, Mater. T. JIM 48 (11) (2007) 3007-3013. 
[16] J. I. Kim, H. Y. Kim, H. Hosoda, S. Miyazaki, Shape memory behaviour of Ti22Nb-(0.5-2.0)O(at\%) biomedical alloys, Mater. T. JIM 46 (4) (2005) 852-857.

[17] E. G. Obbard, Y. L. Hao, R. J. Talling, S. J. Li, Y. W. Zhang, D. Dye, R. Yang, The effect of oxygen on $\alpha^{\prime \prime}$ martensite and superelasticity in Ti24Nb4Zr8Sn, Acta Mater. 59 (1) (2011) 112-125.

[18] J. Coakley, V. A. Vorontsov, K. C. Littrell, R. K. Heenan, M. Ohnuma, N. G. Jones, D. Dye, Nanoprecipitation in a beta-titanium alloy, J. Alloy. Compd. 623 (2015) 146-156.

[19] J. Coakley, K. M. Rahman, V. A. Vorontsov, M. Ohnuma, D. Dye, Effect of precipitation on mechanical properties in the $\beta$-Ti alloy Ti-24Nb-4Zr-8Sn, Mat. Sci. Eng. A 655 (2016) 399-407.

[20] J. Coakley, V. A. Vorontsov, N. G. Jones, A. Radecka, P. A. J. Bagot, K. C. Littrell, R. K. Heenan, F. Hu, A. P. Magyar, D. C. Bell, D. Dye, Precipitation processes in the beta-titanium alloy Ti-5Al-5Mo-5V-3Cr, J. Alloy. Compd. 646 (2015) 946-953.

[21] M. Morinaga, M. Kato, T. Kamimura, M. Fukumoto, I. Harada, K. Kubo, Theoretical design of $\beta$-type titanium alloys, in: F. H. Froes, I. Caplan (Eds.), Titanium '92, Vol. 1, TMS, 1993, pp. 217-224.

[22] D. Kuroda, M. Niinomi, M. Morinaga, Y. Kato, T. Yashiro, Design and mechanical properties of new $\beta$ type titanium alloys for implant materials, Mat. Sci. Eng. A 243 (1998) 244-249.

[23] R. J. Talling, R. J. Dashwood, M. Jackson, D. Dye, On the mechanism of superelasticity in Gum metal, Acta Mater. 57 (4) (2009) 1188-1198.

[24] V. A. Vorontsov, N. G. Jones, K. M. Rahman, D. Dye, Superelastic load cycling of Gum Metal, Acta Mater. 88 (2015) 323 - 333.

[25] K. M. Rahman, V. A. Vorontsov, D. Dye, The dynamic behaviour of a twinning induced plasticity steel, Mat. Sci. Eng. A 589 (2014) 252-261.

[26] Q. Liu, Q. Meng, S. Guo, X. Zhao, $\alpha^{\prime}$ type TiNbZr alloys with ultra-low Young's modulus and high strength, Prog. Nat. Sci. - Mater. 23 (2013) 562-565.

[27] M. González, J. Peña, J. M. Manero, M. Arciniegas, F. J. Gil, Design and characterization of new Ti-Nb-Hf alloys, J. Mater. Eng. Perform. 18 (2009) 490-495.

[28] M. González, J. Peña, F. G. Gil, J. M. Manero, Low modulus Ti-Nb-Hf alloy for biomedical applications, Mat. Sci. Eng. C 42 (2014) 691-695.

[29] P. Laheurte, F. Prima, A. Eberhardt, T. Gloriant, M. Wary, E. Patoor, Mechanical properties of low modulus $\beta$ titanium alloys designed from the electronic approach, J. Mech. Behav. Biomed. 3 (2010) 565-573.

[30] M. Yan, W. Xu, M. S. Dargusch, H. P. Tang, M. Brandt, M. Qian, Review of effect of oxygen on room temperature ductility of titanium and titanium alloys, Powder Metall. 57 (4) (2014) 251-257. 
[31] A. Ramarolahy, P. Castany, F. Prima, P. Lahuerte, I. Peron, T. Gloriant, Microstructure and mechanical behavior of superelastic Ti-24Nb-0.5O and Ti24Nb-0.5N biomedical alloys, J. Mech. Behav. Biomed. 9 (2012) 83-90.

[32] K. M. Rahman, V. A. Vorontsov, D. Dye, The effect of grain size on the twin initiation stress in a TWIP steel, Acta Mater. 89 (2015) 247-257.

[33] J. W. Christian, S. Mahajan, Deformation twinning, Prog. Mater. Sci. 39 (1995) $1-157$.

[34] S. Hanada, O. Izumi, Correlation of tensile properties, deformation modes, and phase stability in commercial $\beta$-phase titanium alloys, Metall. Mater. Trans. A 18 (1987) 265-271.

[35] M. J. Lai, C. C. Tasan, D. Raabe, On the mechanism of $\{332\}$ twinning in metastable $\beta$ titanium alloys, Acta Mater. 111 (2016) 173-186.

[36] S. Hanada, A. Takemura, O. Izumi, The mode of plastic deformation of $\beta$ Ti-V alloys, Mater. T. JIM 23 (9) (1982) 507-517.

[37] V. F. Moiseev, V. I. Trefilov, Change of the deformation mechanism (slip↔twinning) in polycrystalline $\alpha$-iron, Phys. Status Solidi 18 (1966) 881894.

[38] S. G. Song, G. T. G. III, Influence of temperature and strain rate on slip and twinning behavior of Zr, Metall. Mater. Trans. A 26 (1995) 2665-2675. 
Table 1

Theoretical alloy design parameters used to down select the final alloy compositions for the study: electron per atom ratio $(e / a)$, bond order $(B o)$, metallic average $d$ electron orbital energy level $(M d)$ and martensite start temperature $\left(M_{s}\right)$ estimated by extrapolation.

\begin{tabular}{ccccc}
\hline $\begin{array}{c}\text { Composition } \\
\text { (at.\%) }\end{array}$ & $e / a$ & $B o$ & $\begin{array}{c}M d \\
(\mathrm{eV})\end{array}$ & $\begin{array}{c}M_{s} \\
(\mathrm{~K})\end{array}$ \\
\hline Ti-24Nb-2Hf & 4.240 & 2.871 & 2.452 & $\sim 270$ \\
Ti-24Nb-4Hf & 4.240 & 2.877 & 2.463 & $\sim 200$ \\
Ti-26Nb-2Hf & 4.260 & 2.877 & 2.452 & $\sim 190$ \\
Ti-26Nb-4Hf & 4.260 & 2.883 & 2.462 & $\sim 120$ \\
\hline
\end{tabular}

Table 2

Mechanical properties of Ti-(24-26)Nb-(2-4)Hf (at.\%) alloys measured in uniaxial tension at ambient temperature, $\approx 20^{\circ} \mathrm{C}$, in the "as hot-rolled" condition.

\begin{tabular}{ccccccc}
\hline $\begin{array}{c}\text { Nominal } \\
\text { Composition } \\
(\text { at.\% })\end{array}$ & $\begin{array}{c}0.2 \% \\
\text { Yield } \\
(\mathrm{MPa})\end{array}$ & UTS & $\begin{array}{c}\text { Failure } \\
\text { Strain } \\
(\%)\end{array}$ & $\begin{array}{c}\text { Elastic } \\
\text { Modulus } \\
(\mathrm{GPa})\end{array}$ & $\begin{array}{c}\text { Total Work } \\
\text { Hardening } \\
(\mathrm{MPa})\end{array}$ & $\begin{array}{c}\text { Average } \\
\text { Hardening Rate } \\
(\mathrm{GPa})\end{array}$ \\
\hline Ti-24Nb-2Hf & 302 & 476 & 31.5 & 56.3 & 174 & 0.67 \\
Ti-24Nb-4Hf & 376 & 505 & 21.7 & 51.9 & 129 & 0.61 \\
Ti-26Nb-2Hf & 395 & 488 & 19.8 & 50.3 & 93 & 0.78 \\
Ti-26Nb-4Hf & 400 & 466 & 15.2 & 56.1 & 66 & 0.59 \\
\hline
\end{tabular}

Table 3

Mechanical properties of Ti-(24-26)Nb-(2-4)Hf (at.\%) alloys measured in uniaxial tension at ambient temperature, $\approx 20^{\circ} \mathrm{C}$, after annealing at $800^{\circ} \mathrm{C}$ for $1 \mathrm{~h}$. Values in brackets correspond to annealing at $800^{\circ} \mathrm{C}$ for $1 \mathrm{~h}$ followed by ageing at $300^{\circ} \mathrm{C}$ for $24 \mathrm{~h}$.

\begin{tabular}{cccccc}
$\begin{array}{c}\text { Nominal } \\
\text { Composition } \\
(\text { at.\% })\end{array}$ & $\begin{array}{c}0.2 \% \\
\text { Yield } \\
(\mathrm{MPa})\end{array}$ & UTS & $\begin{array}{c}\text { Failure } \\
\text { Strain } \\
(\mathrm{MPa})\end{array}$ & $\begin{array}{c}\text { Total Work } \\
\text { Hardening } \\
(\mathrm{MPa})\end{array}$ & $\begin{array}{c}\text { Average } \\
\text { Hardening Rate } \\
(\mathrm{GPa})\end{array}$ \\
\hline Ti-24Nb-2Hf & 146 & $409(660)$ & $26.4(0.7)$ & 263 & 1.18 \\
Ti-24Nb-4Hf & 239 & $441(695)$ & $28.3(2.6)$ & 202 & 0.87 \\
Ti-26Nb-2Hf & 431 & $497(634)$ & $15.1(15.8)$ & 66 & 0.42 \\
Ti-26Nb-4Hf & 368 & $417(556)$ & $22.5(8.3)$ & 49 & 0.31 \\
\hline
\end{tabular}


Table 4

Mechanical properties of "as hot-rolled" Ti-(24-26)Nb-(2-4)Hf (at.\%) alloys measured in uniaxial tension during immersion in liquid nitrogen at $-196{ }^{\circ} \mathrm{C}$.

\begin{tabular}{cccccc}
\hline $\begin{array}{c}\text { Nominal } \\
\text { Composition } \\
(\text { at.\% })\end{array}$ & $\begin{array}{c}0.2 \% \\
\text { Yield } \\
(\mathrm{MPa})\end{array}$ & UTS & $\begin{array}{c}\text { Failure } \\
\text { Strain } \\
(\%)\end{array}$ & $\begin{array}{c}\text { Total Work } \\
\text { Hardening } \\
(\mathrm{MPa})\end{array}$ & $\begin{array}{c}\text { Average } \\
\text { Hardening Rate } \\
(\mathrm{GPa})\end{array}$ \\
\hline Ti-24Nb-2Hf & 607 & 1065 & 35.5 & 458 & 1.28 \\
Ti-24Nb-4Hf & 626 & 1128 & 40.9 & 502 & 1.16 \\
Ti-26Nb-2Hf & 650 & 1103 & 30.8 & 453 & 1.54 \\
Ti-26Nb-4Hf & 477 & 1004 & 33.4 & 527 & 1.42 \\
\hline
\end{tabular}

Table 5

Proportions of the different twin boundary types indexed by the Bruker Esprit 2.0 software. Data for "as hot-rolled" (AHR), $\beta$-annealed (BA) and liquid nitrogen immersed (LN2) specimens of Ti-(24-26) Nb-(2-4)Hf at.\% alloys are presented.

Fraction of twin boundary type (\%)

\begin{tabular}{lcccccc}
\hline Alloy & $\{332\}$ & $\{211\}$ & $\{411\}$ & $\{222\}$ & $\{310\}$ & $\{321\}$ \\
\hline Ti-24Nb-2Hf (AHR) & 94.9 & 4.9 & 0.1 & - & - & - \\
Ti-24Nb-4Hf (AHR) & 33.0 & 56.6 & 8.8 & 0.8 & 0.4 & 0.4 \\
Ti-26Nb-2Hf (AHR) & 62.1 & 35.7 & 1.4 & 0.5 & 0.1 & 0.2 \\
Ti-26Nb-4Hf (AHR) & 13.1 & 73.1 & 8.9 & 0.6 & - & 4.3 \\
\hline Ti-24Nb-2Hf (BA) & 45.2 & 35.6 & 8.9 & 0.4 & 9.3 & - \\
Ti-24Nb-4Hf (BA) & 35.4 & 60.6 & 3.4 & 0.4 & 0.2 & - \\
Ti-26Nb-2Hf (BA) & 38.0 & 68.7 & 2.1 & 1.3 & - & - \\
Ti-26Nb-4Hf (BA) & 74.9 & 18.1 & 6.5 & 0.1 & 0.3 & - \\
\hline Ti-24Nb-2Hf (LN2) & 46.9 & 52.8 & 0.1 & - & 0.2 & - \\
Ti-24Nb-4Hf (LN2) & 55.0 & 42.1 & 2.1 & - & 0.7 & 0.1 \\
Ti-26Nb-2Hf (LN2) & 96.9 & 2.1 & 0.3 & - & 0.6 & - \\
Ti-26Nb-4Hf (LN2) & 89.3 & 4.5 & 4.6 & 0.1 & 1.4 & - \\
\hline
\end{tabular}



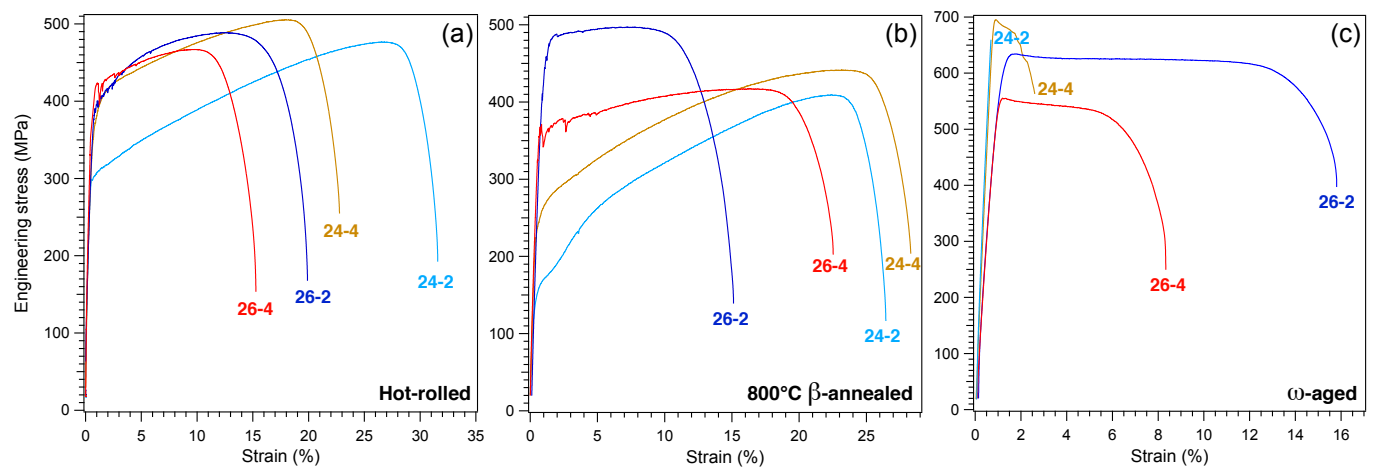

Fig. 1. Deformation behaviour of Ti- $(24-26) \mathrm{Nb}-(2-4) \mathrm{Hf}$ at.\% alloys in uniaxial tension, strained at $10^{-3} \mathrm{~s}^{-1}$ at ambient temperature, $\approx 20^{\circ} \mathrm{C}$ : in the "as hot-rolled" condition (a), after annealing at $800^{\circ} \mathrm{C}$ for $1 \mathrm{~h}$ (b), and after annealing at $800^{\circ} \mathrm{C}$ for $1 \mathrm{~h}$ followed by ageing at $300^{\circ} \mathrm{C}$ for $24 \mathrm{~h}(\mathrm{c})$.

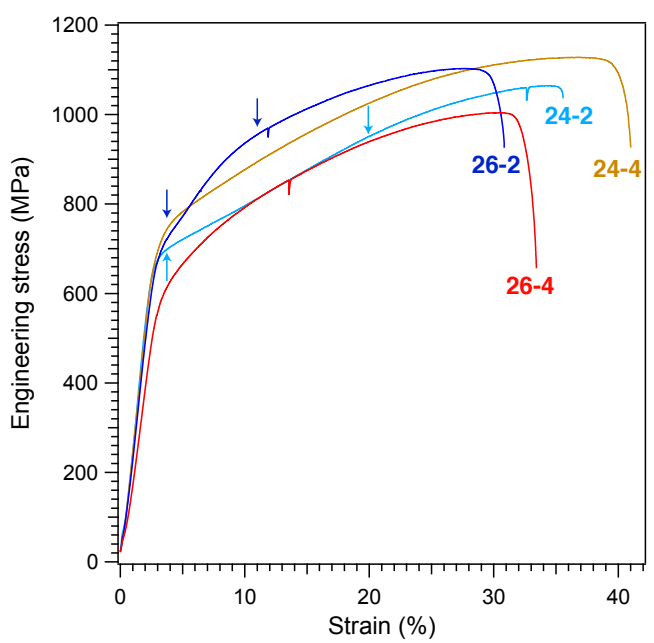

Fig. 2. Deformation behaviour of "as hot-rolled" Ti-(24-26)Nb-(2-4)Hf at.\% alloys in uniaxial tension, strained at $10^{-3} \mathrm{~s}^{-1}$ and during immersion in liquid nitrogen at $-196^{\circ} \mathrm{C}$. 


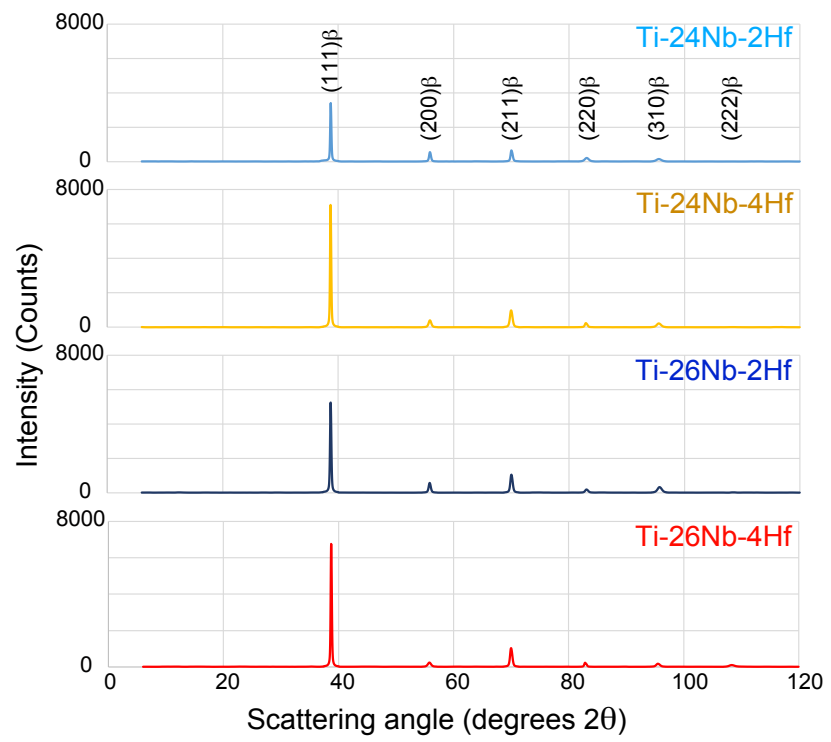

Fig. 3. X-ray diffraction spectra obtained from the "as hot-rolled" Ti- $(24-26) \mathrm{Nb}-(2-4) \mathrm{Hf}$ at.\% alloys. All four alloys were found to be in the fully- $\beta$ condition, showing only reflections from the b.c.c. Ti phase. 


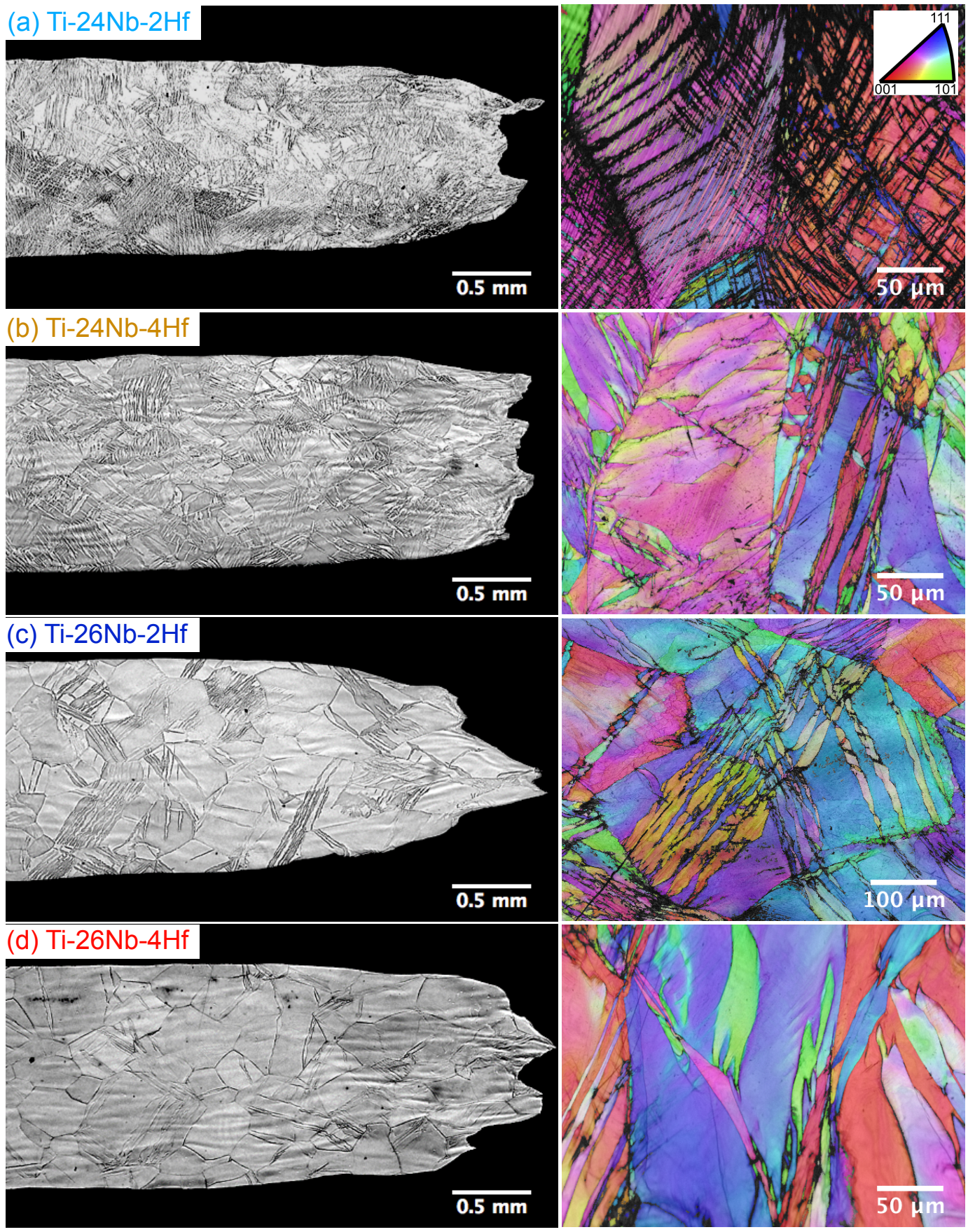

Fig. 4. Post-mortem microstructures of Ti-(24-26)Nb-(2-4)Hf at.\% alloys that have been tested to failure in uniaxial tension at ambient temperature in the "as hot-rolled" condition. Light micrographs (left) are presented alongside EBSD maps (right). The light microscope images show the regions in the miniature tensile test specimens adjacent to the fracture surface. The EBSD data comprise the band contrast maps overlaid with the inverse pole figure maps coloured relative to the specimen surface normal. The tensile stress direction is parallel to the vertical image axis of orientation maps. 

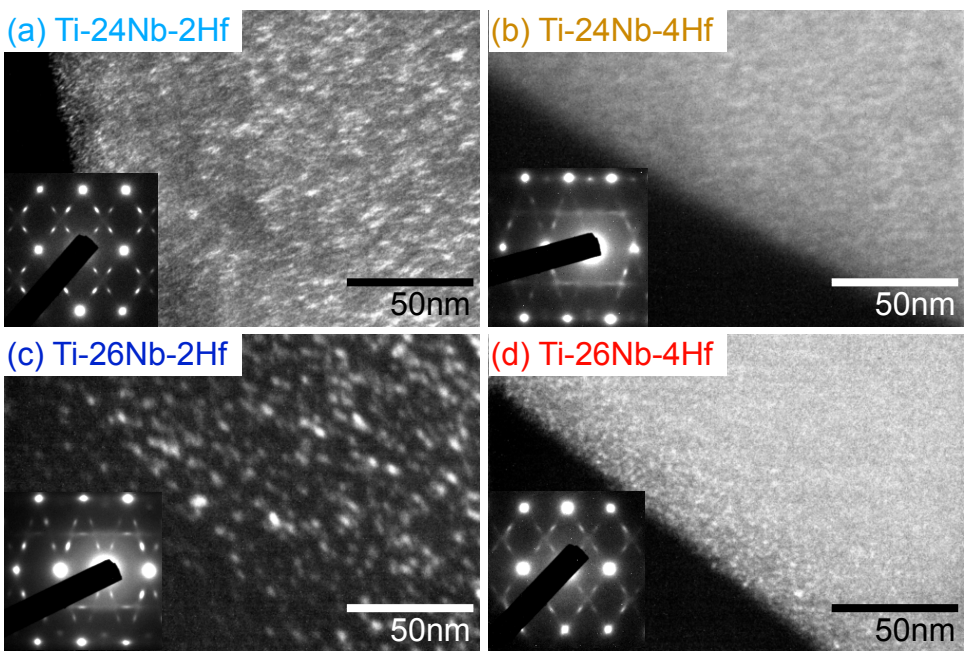

Fig. 5. Dark-field transmission electron micrographs of as-manufactured Ti-(24-26)Nb-(2-4)Hf at.\% alloys showing the present distributions of nano-scale $\omega$ phase precipitates. Images (a) and (d) were taken parallel to the $\langle 110\rangle$ zone axis, while (b) and (c) were imaged parallel to the $\langle 113\rangle$ zone axis, as is shown by the supplementary diffraction patterns. The smaller, less-bright diffraction spots correspond to the $\omega$ phase. 

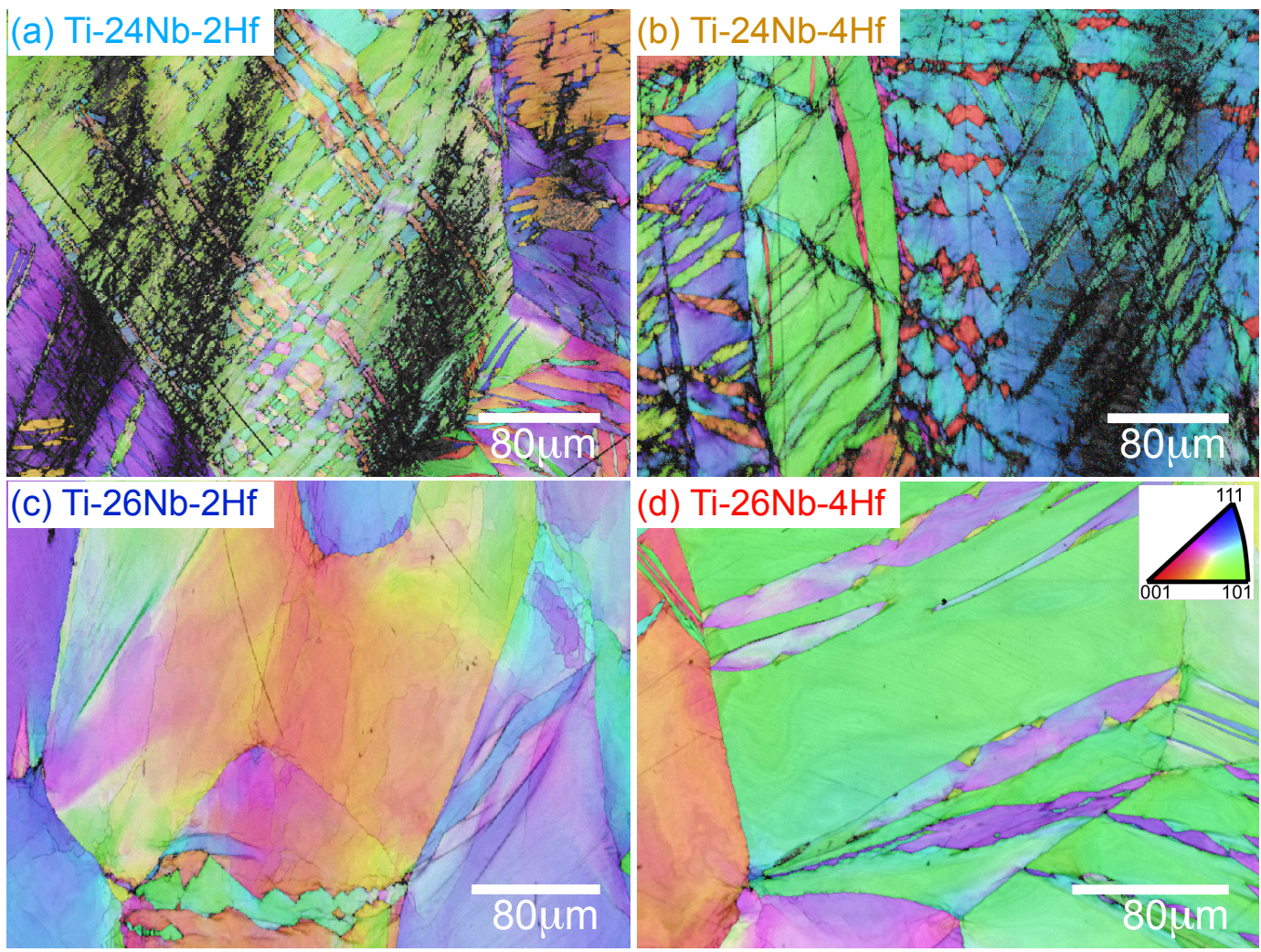

Fig. 6. EBSD maps showing post-mortem microstructures of Ti-(24-26)Nb-(2-4)Hf (at.\%) alloys deformed in uniaxial tension at ambient temperature, $\approx 20^{\circ} \mathrm{C}$, after annealing at $800^{\circ} \mathrm{C}$ for $1 \mathrm{~h}$. The EBSD data comprise the band contrast maps overlaid with the inverse pole figure maps coloured relative to the specimen surface normal. The tensile stress direction is parallel to the vertical image axis. 

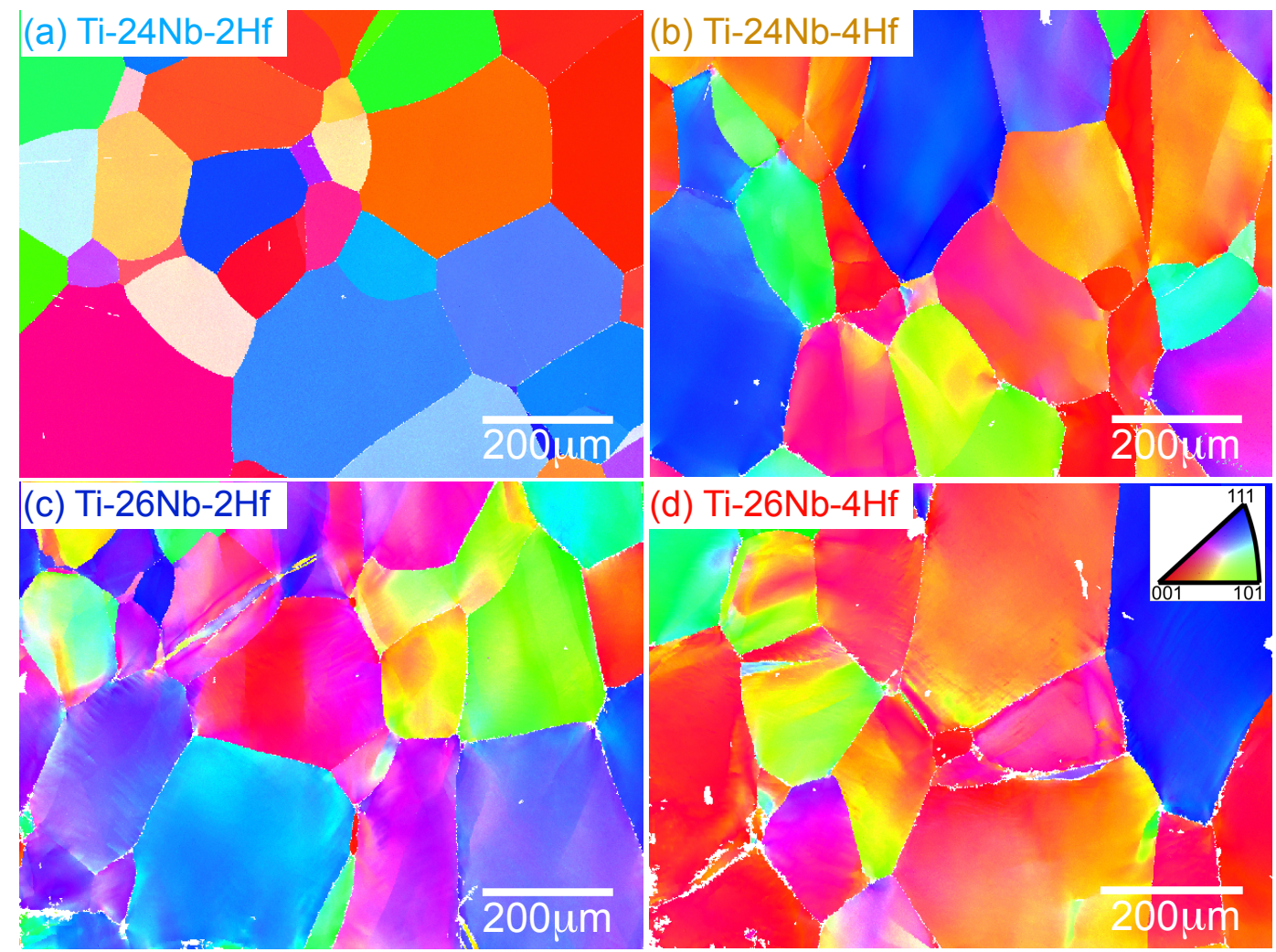

Fig. 7. EBSD maps showing post-mortem microstructures of Ti-(24-26) Nb-(2-4)Hf (at.\%) alloys deformed in uniaxial tension at ambient temperature, $\approx 20^{\circ} \mathrm{C}$, after annealing at $800^{\circ} \mathrm{C}$ for $1 \mathrm{~h}$ followed by ageing at $300^{\circ} \mathrm{C}$ for $24 \mathrm{~h}$. The images are inverse pole figure maps coloured relative to the specimen surface normal. The tensile stress direction is parallel to the vertical image axis. 

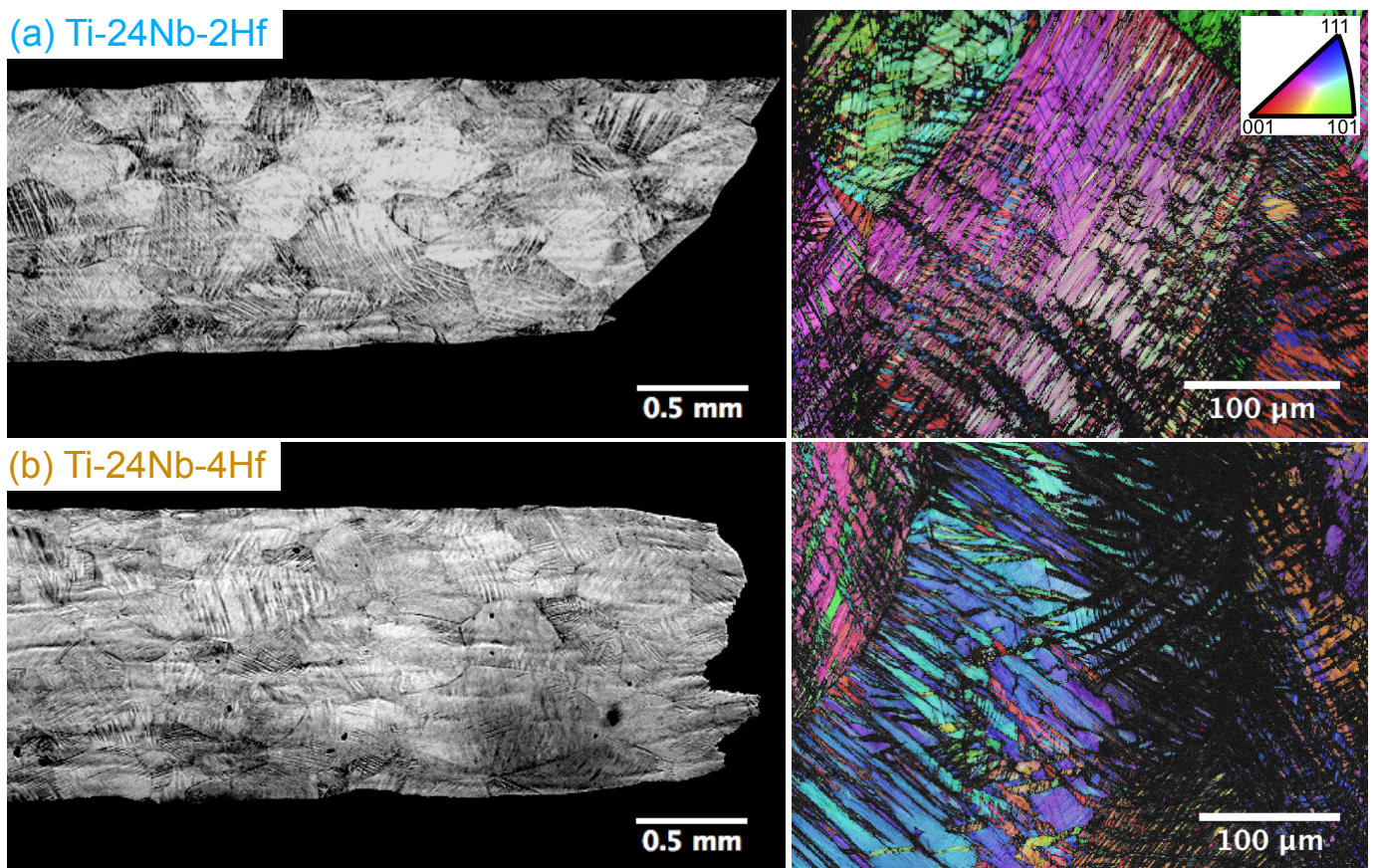

\section{(c) $\mathrm{Ti}-26 \mathrm{Nb}-2 \mathrm{Hf}$}

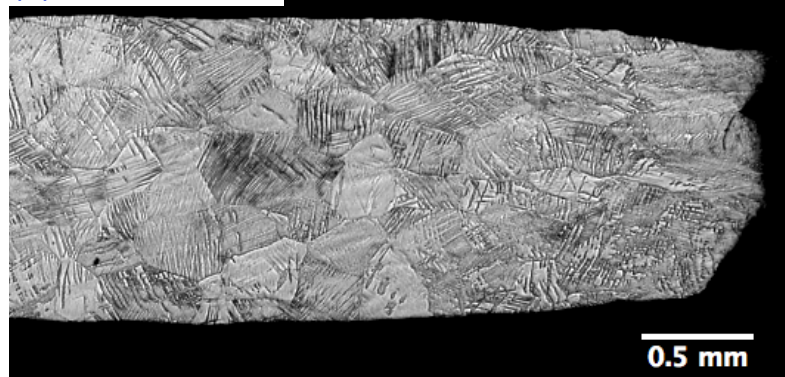

\section{(d) Ti-26Nb-4Hf}

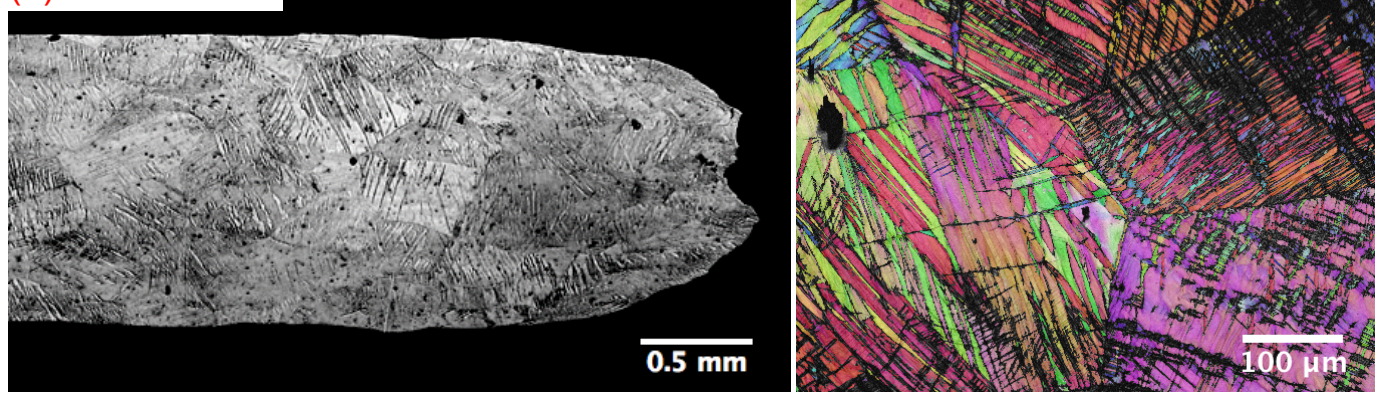

Fig. 8. Post-mortem microstructures of Ti-(24-26)Nb-(2-4)Hf at.\% alloys that have been tested to failure in uniaxial tension during immersion in liquid nitrogen at $-196{ }^{\circ} \mathrm{C}$. Light micrographs (left) are presented alongside EBSD maps (right). The light microscope images show the regions in the miniature tensile test specimens adjacent to the fracture surface. The EBSD data comprise the band contrast maps overlaid with the inverse pole figure maps coloured relative to the specimen surface normal. The tensile stress direction is parallel to the vertical image axis of orientation maps. 

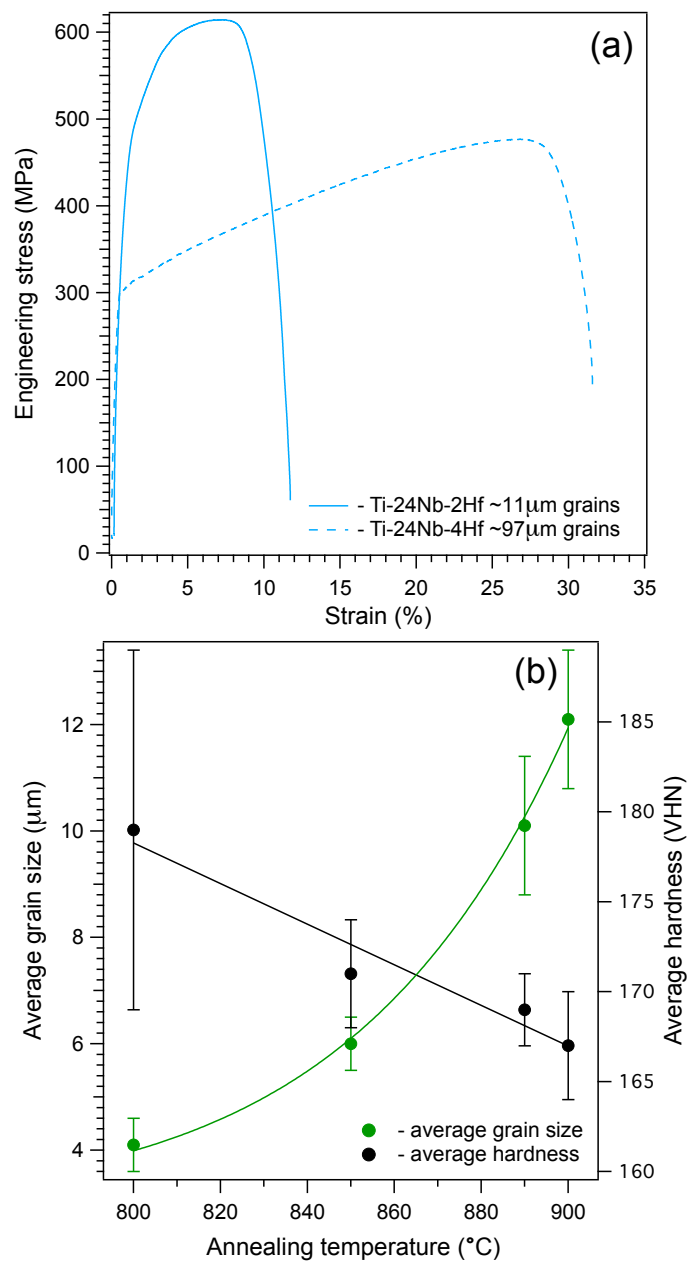

Fig. 9. (a) Effect of grain size refinement processing (cold rolling to $25 \%$ thickness reduction followed by $2 \mathrm{~min}$ flash annealing at $900{ }^{\circ} \mathrm{C}$ repeated twice) on the ambient temperature tensile deformation of Ti-24Nb-2Hf at.\%. The results are represented by the solid line, compared to the "as hot-rolled" material represented by the dashed line. (b) Shows the effects of of $1 \mathrm{~min}$ flash annealing temperature on the average grain size in of Ti-24Nb-2Hf at.\% cold rolled to $70 \%$ reduction and the corresponding effect on the Vickers hardness. 


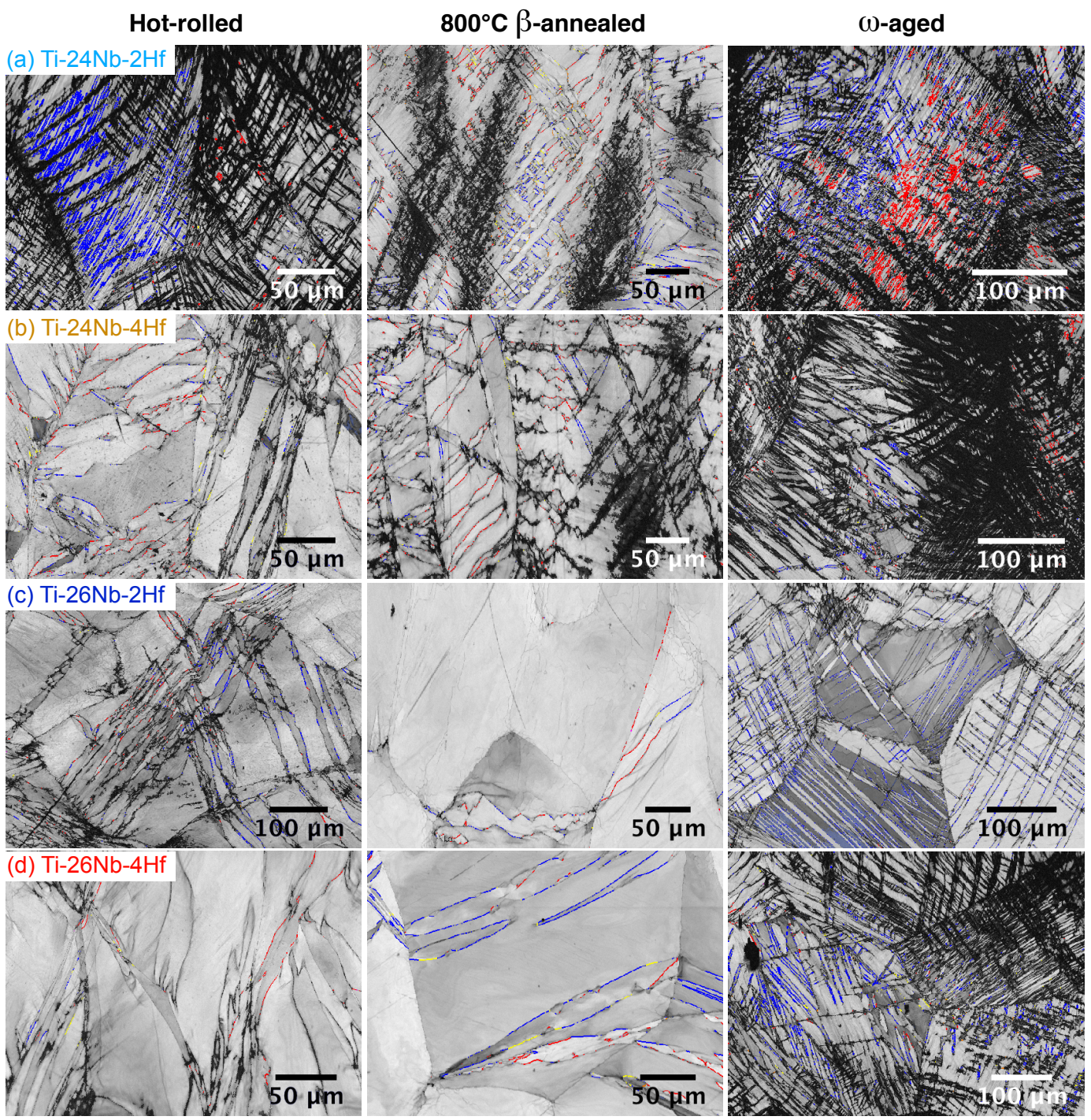

Fig. 10. Twin boundary analysis as carried out by the Bruker Esprit 2.0 software. The sucessfully indexed twin boundaries are shown in colour: blue - $\{332\}$, red - $\{211\}$ and yellow - $\{411\}$. the data are overlaid onto the EBSD band contrast maps and $\{110\}\langle\overline{1} 1 \overline{1}\rangle$ Schmid factor map (black=0.3, white=0.5) with respect to the loading direction (vertical image axis). 